\title{
Role of the Nurse in Forensic Psychiatry
}

\author{
Sinisa Franjic* \\ Faculty of Law, Bosnia and Herzegovina, Europe
}

*Corresponding author: Sinisa Franjic, Faculty of Law, Bosnia and Herzegovina, Europe.

Received Date: July 03, 2018

Published Date: November 27, 2018

\begin{abstract}
The job description of the nurses includes the care, monitoring, supervision and counseling of patients and other sick persons, as well as keeping documentation and performing health care. Depending on the workplace (hospitals, health centers, ambulance, home of the retired), the nursing job can also include prevention, rehabilitation, health education and health promotion. Most nurses mainly deal with nursing care, and what they share is a systematic approach to addressing health problems within their scope. Nurses monitoring the psychological and physical condition of their patients and so they come to important data needed for further treatment.
\end{abstract}

Keywords: Nurse; Nursing; Patient; Forensics

\section{Introduction}

Motivations of APNs (Advanced Practice Nurses) who serve as advocates for their patients stem from various ethical vantage points, and should be examined self-reflectively as interventions are developed and evaluated [1]. From a deontological perspective, principles such as justice, beneficence, and autonomy are served by advocating for more resources for the poor and vulnerable. From a teleological view, APNs can work for ends such as policy options that result in improved health care and successful social and economic skills. APNs can recognize their own feelings (sympathy and empathy) for vulnerable patients as the ethic of care prescribes, and their character traits and those of their clients as virtue ethics expects. On the broader scale, nurses may act from concern about the community's health (communitarianism) and with assessments that distinguish characteristics of each case (casuistry). Any or all of these ethical benchmarks may be selected by nurses to determine actions that are appropriate for use with their patients, families, and communities.

People's views and subjective experience of their illness, disability or condition may be very different to those of a nurse involved in their care or treatment [2]. There may be very important differences in the values underpinning the beliefs and actions of the various individuals, including professionals, and processes involved when the law is being used. This makes mental health nursing significantly different to nursing people with physical health problems. This can be viewed as a positive asset for mental health nurses because it means the process of decision-making and caring for people is potentially a more inclusive, holistic process, by incorporating a range of different values (including those underpinning the law) and points of views including service users, family carers and other practitioners.

In order to live well together, we must have reasonable expectations about the conduct of others [3]. Those expectations are grounded on proprieties of practice, adherence to which requires us to have moral and emotional capacities that enable responsiveness to others' rights and needs. Capacities such as empathy, a sense of justice, care and concern, prudence, an interest in making and keeping promises, and, more generally, dispositions that connect us to others can prevent social anomie. Even the visceral capacity to feel disgust at scenes of brutality and suffering is essential to our sense of community. People who lack these capacities frighten us, and for good reasons: they are unpredictable, strange, threatening. People who are labeled psychopathic, generally present us with a difficult choice: to exclude them from our community or to render their threatening character harmless.

\section{Mental Disorder and Mental Illness}

Mental disorder represents the main point of contact between psychiatry and the law [4]. The early days of psychiatry in the nineteenth century were heavily influenced by eugenic considerations - it was assumed that a variety of deviant conducts could be explained by a tainted gene pool in the lower social classes. This degeneracy theory, which characterized early biological 
psychiatry, linked together the mad, the bad and the dim. However, during the First World War and its aftermath such an underlying assumption began to falter. In the forensic field, there emerged a resistance to the old eugenic ideas of degeneracy, which accounted for criminality in terms of an inherited disposition to bad conduct. This was replaced by an increasing interest in environmental or psychological explanations for law-breaking. Since that time, psychiatric experts have played a major role in identifying and explaining criminal conduct. And once there was that shift away from bio-genetic determinism, then this opened up questions, still pertinent today, about psychological explanations. Given that the latter contain elements of determinism as well as assumptions about human agency, then case by case the balance allotted to each is always open to consideration and varying perspectives. The norms of the criminal justice system permit this ambiguity. For example, mental illness may be considered as a reason to exculpate criminal action in a context, in which usually intention, and therefore intentionality, is the focus of interest to judges and juries.

Mental illness is one of the major health issues facing every community [5]. It is the leading cause of disability in North America and Europe, and costs the United States more than half a trillion dollars per year in treatment and other expenses. Mental disorders are associated with smoking, reduced activity, poor diet, obesity, and hypertension, and also contribute to unintentional and intentional injury. Mental disorders reduce average life expectancy, in some cases (involving substance use disorders, anorexia nervosa, schizophrenia, and bipolar mood disorder) by the same amount as does smoking more than 20 cigarettes a day. Clearly, there is "no health without mental health." Approximately 20\% of American adults (about 45 million people) have diagnosable mental disorders during a given year, and about $5 \%$ of adults in the United States have serious mental illness, that is, illness that interferes with some aspect of social functioning. Only $38 \%$ of those diagnosed with a mental disorder receive treatment. Some of these people require only minimal counseling, followed by regular attendance of supportive self-help group meetings to remain in recovery, while others suffer repeated episodes of disabling mental illness. These individuals require more frequent medical treatment and more significant community support. Finally, there are the most severely disturbed individuals, who require repeated hospitalization.

Forensic psychiatry works at the interface of law and medicine, involves unique problems of boundaries and dual agency in the professional-client relationship, and presents uncertainties and conflicting opinions about its accountability to society [6]. Consequently, legal issues, the range of stakeholders, and the impact of psychiatric medicine on individual autonomy and public safety pose complex challenges for forensic professionals. These require alertness to boundaries and a more robust and dynamic professional ethics.

\section{Nursing and forensics}

Nurses providing patient care in acute care settings care for the young and the old, the sick and the injured [7]. And they must do it without compromising valuable forensic evidence, jeopardizing the police investigation that may ensue, or reducing the patients' chances of getting justice in the court system if they seek it later. With the incorporation of forensic nursing into the hospital, the scope of the practice of nursing has been broadened. A nurse trained in forensics is one who can recognize traumatic conditions and evidence, document their presence, collect and preserve shortlived findings, and understand how the patient's illness or injury happened.

When patients who are victims of assault, abuse, violent crimes, or even motor vehicle collisions present to the hospital, their wounds, clothing, and bodies may be ripe with forensic evidence. This forensic evidence can be used to connect perpetrators with their victims, to protect innocent parties, to help determine who was the driver versus the passenger in an automobile crash, and to ensure forensic questions regarding injury causation can be answered. Unfortunately, forensic evidence is usually fragile (a dusting of soot, blood spatter patterns, biologic fluids, wound characteristics), and forensic evidence can be lost or contaminated while nurses and physicians provide care in the acute care setting.

Forensic nursing is now a well-developed specialty in forensic sciences [8]. A well-trained forensic nurse should be able to understand the principles and procedures of crime scene investigation. This is because a forensic nurse should interact with other specialists and other experts in the field of forensic sciences and should be able to interact with police officers, prosecutors, defense lawyers, crime scene technicians, crime scene investigators, and other experts in the fields of forensic sciences during the process of investigating crimes and adjudicating criminal cases.

\section{Forensic Mental Health and Nursing}

Nursing, by definition, is the protection, promotion, and optimization of health and abilities, prevention of illness and injury, alleviation of suffering through the diagnosis and treatment of human response, and advocacy in the care of individuals, families, communities, and populations [9]. Psychiatric mental health nursing is a specialty within nursing. Psychiatric mental health registered nurses (PMHN) work with individuals, families, groups, and communities, assessing their mental health needs. The PMHN develops a nursing diagnosis and plan of care, implements the nursing process, and evaluates it for effectiveness.

Forensic psychiatrists work most closely with registered nurses who have chosen psychiatric mental health nursing as a specialty area and with advanced practice psychiatric mental health nurses who have chosen forensics as a subspecialty. Forensic nursing is a recognized specialty in nursing. This specialty allows for application of nursing art and science to clinical legal situations. The nurse's level of education and practice experience greatly influences the role of the nurse on the health care team and the criminal justice team.

Forensic mental health nursing is the intersection of mental health and the legal system [10]. Forensic psychiatric nurses work with offenders who have been deemed mentally disordered and need additional attention separate from the judicial/penitentiary system. Forensic psychiatric nurses work with mentally disordered offenders in secure psychiatric services where they assess the 
patient (victim or perpetrator) and gather evidence that may influence conviction, sentencing, recidivism, treatment, and prevention. Forensic psychiatric nurses use their training to aid in the rehabilitation of criminal offenders, assess the wellbeing of crime victims, and serve as expert consultants for criminal proceedings. They most commonly work for law enforcement agencies and at facilities such as prisons, mental hospitals, and juvenile detention centers.

Nurses often interface with patients who exhibit mental health issues in many practice settings: hospitals, clinics, physician and nurse practitioner offices, corrections settings, etc. The patient may present as a psychiatric emergency or may present for other healthcare problems, during which time the patient may exhibit long-standing mental disorders. Many of these patients may have forensic issues related to their care. They may have entered the clinical setting with a weapon, been injured during an altercation with law enforcement or directly with a victim, been a victim of a crime, or been involved in one of many other scenarios in which a person with mental disorders requires medical attention while also having legal problems. Frequently, the healthcare team must deal with the personality disorders common in offenders, concerns regarding violence and safety, and those with factitious disorders trying to feign mental illness to avoid jail or legal consequences.

\section{Conclusion}

Nurses participate in the implementation of many medical procedures (pressure measurement, giving injections, wound healing) and actively participate in providing nursing care in all areas of medicine. The job of a nurse is such that it always has to be extremely careful and every patient needs to approach with due respect. Patients suffering from a psychiatric disorder or having some mental illness require special treatment because they are people who, because of their psychophysical condition, make criminal acts. The work of nurses includes a wide range of events - from engagement in the overall treatment of the patient to participation in the expert witnessing procedure. Because of the complexity of the job, and under the assumption of good knowledge of medical disciplines related to solving specific cases in courts, the nurse of this profile should know well criminal law disciplines, especially criminal law, criminal procedural law, criminalistics and forensics.

\section{Acknowledgement}

None.

\section{Conflict of Interest}

No conflict of interest.

\section{References}

1. Kjervik D (2010) The Interface of Nursing Law and Ethics. In: Kjervik D, Brous EA (Eds.), Law and Ethics in Advanced Practice Nursing. Springer Publishing Company, New York, p. 39.

2. Williamson T, Daw R (2013) Law, Values and Practice in Mental Health Nursing - A Handbook. Open University Press, McGraw-Hill Education, p. 91.

3. Douard J, Schultz PD (2013) Monstrous Crimes and the Failure of Forensic Psychiatry. In: Douard J, Schultz PD (Eds.), Springer Science+Business Media, Dordrecht, p. 133.

4. Rogers A, Pilgrim D (2014) A Sociology of Mental Health and Illness. In: Rogers A, Pilgrim D (Eds.), (5 $5^{\text {th }}$ edn) Open University Press, McGraw-Hill Education, Maidenhead, p. 158.

5. McKenzie JF, Pinger RR, Seabert DM (2016) An Introduction to Community \& Public Health. In: McKenzie JF, Pinger RR, Seabert DM (Eds.), ( $9^{\text {th }}$ edn), Jones \& Bartlett Learning, Burlington, pp. 288-289.

6. Candilis PJ, Martinez R (2016) Recent Developments in Forensic Psychiatry Ethics.In: Griffith EEH, Norko MA, Buchanan A, Baranoski MV, Zonana HV (Eds.), Bearing Witness to Change - Forensic Psychiatry and Psychology Practice. ( $1^{\text {st }}$ edn), CRC Press, Taylor \& Francis Group, India, pp. 1-408.

7. Smock ME, Smock WS (2015) Assessment of Wound and Injury. In: Amar AF, Sekula LK (Eds.), A Practical Guide to Forensic Nursing - Incorporating Forensic Principles Into Nursing. Sigma Theta Tau International, Indianapolis, p. 360.

8. Okoye MI (2009) Crime Scene Investigation. In: Garbacz Bader DM, Gabriel S (Eds.), Forensic Nursing - A Concise Manual. CRC Press, Taylor \& Francis Group, Boca Raton, p. 56.

9. Brown K (2015) Nobody Wins Without a Good Team. In: Sadoff RL (Ed.), The Evolution of Forensic Psychiatry - History, Current Developments, Future Directions. Oxford University Press, Oxford, p. 232.

10. Sekula LK, Amar AF (2016) Forensic Mental Health Nursing. In: Amar AF, Sekula LK (Eds.), A Practical Guide to Forensic Nursing - Incorporating Forensic Principles Into Nursing. Sigma Theta Tau International, Indianapolis, p. 226. 